Rev. Bras. Saúde Prod. Anim., Salvador, v.16, n.2, p.397-407 abr./jun.., 2015 http://www.rbspa.ufba.br

\title{
Estudos da coloração do pelame em relação às respostas produtivas de ovinos mestiços sob estresse calórico
}

\author{
Coat colour's studies in relation to the productive variables of crossbred sheep under \\ heat stress
}

DANTAS, Nayanne Lopes Batista ${ }^{1 *}$; SOUZA, Bonifácio Benicio de ${ }^{2}$; CÉZAR, Marcílio Fontes $^{2}$; OLIVEIRA, Gabriel Jorge Carneiro de ${ }^{3}$; ARAÚJO, Rafael Pádua $\mathrm{de}^{4}$; NOBRE, Ismael de Sousa ${ }^{4}$; MEDEIROS, Simara Freire de ${ }^{2}$; ROBERTO, João Vinícius Barbosa ${ }^{4}$

\footnotetext{
${ }^{1}$ Universidade Federal de Campina Grande, Programa de Pós-graduação em Medicina Veterinária, Patos, Paraíba, Brasil.

${ }^{2}$ Universidade Federal de Campina Grande, Centro de Saúde e Tecnologia Rural, Unidade Acadêmica de Medicina Veterinária, Patos, Paraíba, Brasil.

${ }^{3}$ Universidade Federal do Recôncavo da Bahia, Centro de Ciências Agrárias, Ambientais e Biológicas, Cruz das Almas, Bahia, Brasil.

${ }^{4}$ Universidade Federal de Campina Grande, Patos, Paraíba, Brasil.

*Endereço para correspondência: nayanne.lb@gmail.com
}

\section{RESUMO}

Objetivou-se avaliar as respostas produtivas de 30 ovinos mestiços $1 / 2$ Santa Inês $+1 / 2$ Dorper, com idade média de quatro meses, 15 com pelame preto e 15 com pelame branco, submetidos a estresse térmico. Os animais sofreram exposição à radiação solar direta durante uma hora $(14 \mathrm{~h} 00-15 \mathrm{~h} 00)$ por semana durante oito semanas. Foram feitas as medições de altura do dorso, altura da garupa, largura do tórax, largura da garupa, perímetro do tórax, perímetro da coxa, perímetro da garupa e perímetro escrotal. Os animais foram abatidos e houve a pesagem dos seguintes componentes: sangue, pele, fígado, coração, rins, cabeça, patas, pulmão, trato gastrointestinal e vazio, testículos e pênis/uretra. Foram avaliados os pesos de carcaça quente e carcaça fria e calculadas as perdas por resfriamento $\mathrm{e}$ rendimento de carcaça quente e carcaça fria, além dos cortes comerciais: paleta, perna, pescoço, lombo e costela. Também foram avaliados o acabamento e conformação da carcaça e avaliação da cor, marmoreio, textura e espessura de gordura subcutânea. Os ovinos pretos apresentaram maior peso de rins e menor peso de testículos, carcaça quente, paleta, perna, costela e menor medida de largura da garupa em relação aos animais de pelame branco. O estresse térmico pode provocar distúrbios no metabolismo dos ovinos, afetando sua condição corporal e alterando seu desenvolvimento.

Palavras-chave: abate, carcaça, Dorper, pelagens, Santa Inês

\section{SUMMARY}

The aim of this research was to evaluate the yield responses of crossbred sheep Santa Ines with Dorper, with an average age of four months, 15 of dark coat and 15 of white coat, under heat stress. The animals were exposed to solar radiation for one hour per week (14.00 15.00) for eight weeks. Measurements of height of the dorsum, rump height, chest width, rump width, thoracic perimeter, thigh perimeter, hind perimeter and scrotal perimeter were made. The animals were slaughtered and were weighed the following components: blood, skin, liver, heart, kidneys, head, legs, lungs, testicles and penis / urethra. The gastrointestinal tract was weighed full and empty. The hot carcass weight and cold carcass weight and calculated cooling losses and hot carcass yield and cold were evaluated; beyond of the commercial cuts: palette, leg, neck, loin and rib. Finishing and carcass 
conformation and color assessment, marbling, texture and subcutaneous fat thickness were also evaluated. Black sheeps had heavier kidneys than the white sheeps. Testicles, the hot carcass, palette, leg, rib and rump width of black sheeps were lighter towards animals white fur. Heat stress can cause disturbances in the metabolism of sheep, affecting their body condition and altering its development.

Keywords: carcass, coats, Dorper, Santa Inês, slaughter

\section{INTRODUÇÃO}

A ovinocultura no Nordeste do Brasil possui marcada relevância visto que essa região detém o maior efetivo ovino de todo o país. Esta alta produção está diretamente relacionada à crescente demanda por carne principalmente para consumo interno e, em menor escala, para exportação. De acordo com dados do MAPA (2009), o rebanho mundial de ovinos diminuiu cerca de $8 \%$ nos últimos 20 anos, porém a produção de carne ovina aumentou em 27\%. De 1997 a 2008, a importação de carne ovina passou de US\$ 6 milhões para mais de US\$ 23 milhões, demonstrando assim a aceitação deste produto pelo mercado consumidor.

No geral, as raças especializadas de corte apresentam um crescimento rápido e bom acabamento de carcaça, mas nem sempre são encontradas em diferentes regiões do Brasil e a maioria não está adequada às adversidades climáticas. Ovinos cruzados normalmente atingem peso corporal de abate mais cedo que os de raça pura, no entanto, ainda são necessários mais estudos no intuito de produzir animais precoces com bom rendimento de carcaça e qualidade da carne (PINHEIRO et al., 2008).

Araujo Filho et al. (2007) afirmam que a caracterização fenotípica de um determinado grupo racial é indispensável para o processo de melhoramento, podendo ser realizada por meio do estudo da morfometria, coloração dos animais ou ainda outros índices zootécnicos. Nesse âmbito, o pelame do animal constitui um meio importante de troca de calor com o ambiente e estudos demonstram que animais com pelame escuro estão mais susceptíveis aos efeitos do estresse calórico devido a sua maior capacidade de absorção dos raios solares, enquanto animais de pelame claro são mais eficientes em refletir esses raios.

As modificações fisiológicas decorrentes do estresse térmico incluem alterações no fracionamento dos nutrientes e no perfil hormonal, caracterizadas principalmente por declínio e aumento dos hormônios anabólicos e catabólicos, respectivamente (BERNABUCCI et al., 2010). Dessa forma, além do fator nutricional, o genótipo e o ambiente também podem influenciar as características de conformação e acabamento das carcaças ovinas (COSTA et al., 2010).

Objetivou-se através dessa pesquisa avaliar as respostas produtivas de 30 ovinos mestiços $1 / 2$ Santa Inês $+1 / 2$ Dorper com pelames branco e preto, submetidos a estresse térmico.

\section{MATERIAL E MÉTODOS}

O experimento foi desenvolvido durante os meses de Setembro e Outubro de 2012, no Núcleo de Pesquisa para o Desenvolvimento do Semiárido (NUPEARIDO) e as carcaças foram avaliadas no laboratório de avaliação de carcaças do Centro de Saúde e Tecnologia Rural (CSTR), da Universidade Federal de Campina Grande (UFCG), localizado no município de Patos, na Paraíba, região semiárida nordestina, com latitude $07^{\circ}$ 
$05^{\prime} 28^{\prime}$ ' S, longitude $37^{\circ} 16^{\prime} 48^{\prime}$ ' W, altitude de $250 \mathrm{~m}$, que se caracteriza por apresentar um clima BSH (Köppen), com temperatura anual média máxima de $32,9^{\circ} \mathrm{C}$ e mínima de $20,8^{\circ} \mathrm{C}$ e umidade relativa de $61 \%$ (BRASIL, 1992).

Foram utilizados 30 ovinos $1 / 2$ Santa Inês $\mathrm{x} 1 / 2$ Dorper, $15 \mathrm{com}$ pelame preto e 15 com pelame branco. Todos os ovinos receberam dieta composta de feno de Tífton (Cynodon spp.), suplementação mineral e água ad libitum. Os animais foram vacinados e vermifugados no início do experimento e permaneceram alojados em baias de madeira, contendo comedouros e bebedouros individuais durante todo o período experimental, que durou 60 dias.

Foi calculado o ITGU (índice de temperatura de globo negro e umidade) nos ambientes de sol e sombra nas instalações onde se encontravam os animais. Utilizou-se a fórmula descrita por Buffington et al. (1981): ITGU = TGN+ 0,36(Tpo) $+41,5$, na qual TGN significa a temperatura de globo negro e Tpo, a temperatura do ponto de orvalho. Essas temperaturas, por sua vez, foram registradas através de termômetros de globo negro, instalados em ambientes de sombra e de sol, acoplados a um datalogger.

Durante o experimento, os animais foram submetidos a estresse térmico através da exposição à radiação solar direta, durante uma hora, entre $14 \mathrm{~h} 00 \mathrm{e}$ 15h00. Ao final do período experimental, foram feitas as seguintes medições: altura do dorso, altura da garupa, largura do tórax, largura da garupa, perímetro do tórax, perímetro da coxa, perímetro da garupa $\mathrm{e}$ perímetro escrotal. As medidas de comprimento e de perímetro foram feitas com fita métrica e as da largura, com auxílio de um paquímetro.
Os ovinos permaneceram em jejum de sólidos por 18 horas. Antes do abate, os animais foram pesados. Foi realizado o atordoamento e a sangria, através da secção da veia jugular e artéria carótida. Após a esfola, procedeu-se a evisceração e então houve a pesagem dos seguintes componentes e órgãos: sangue, pele, fígado, coração, rins, cabeça, patas, pulmão, trato gastrointestinal (TGI) cheio, TGI vazio, testículos e pênis/uretra sendo esses denominados de não componentes da carcaça.

Após esse processo, as carcaças foram pesadas para obtenção do peso de carcaça quente (PCQ). Em seguida, as carcaças foram mantidas em câmara de resfriamento e pesadas após 24 horas para determinação do peso da carcaça fria (PCF). Foram também calculadas as perdas por resfriamento (PPR) através da fórmula: $\mathrm{PPR}=\mathrm{PCQ}-\mathrm{PCF}$; rendimento de carcaça quente: $\mathrm{RCQ}=$ (PCQ/PVA) X 100 e rendimento de carcaça fria: $\mathrm{RCF}=(\mathrm{PCF} / \mathrm{PVA}) \times 100$.

Posteriormente, houve a avaliação do acabamento e conformação da carcaça. De acordo com McManus et al. (2010), a conformação da carcaça expressa o desenvolvimento das massas musculares e é obtido pela verificação dos perfis musculares, os quais definem anatomicamente as regiões de uma carcaça, sendo descritas como convexas, sub-convexas, retilíneas, subcôncavas e côncavas. O acabamento, por sua vez, resulta da avaliação visual da quantidade e distribuição harmônica da gordura na carcaça, estando essa associada com o sabor, suculência e maciez da carne (McMANUS et al., 2010). O acabamento foi descrito através dos índices de 1 a 5 , sendo 1 para gordura ausente e 5, gordura excessiva ( $>10 \mathrm{~mm}$ de espessura).

Avaliou-se também a coloração do músculo (COR); o marmoreio 
Rev. Bras. Saúde Prod. Anim., Salvador, v.16, n.2, p.397-407 abr./jun.., 2015 http://www.rbspa.ufba.br ISSN 15199940

(MARM), que é a quantidade de gordura intramuscular presente no músculo e a textura (TEXT), que consiste no tamanho dos feixes de fibras que se encontram longitudinalmente no músculo; sendo atribuídos escores entre 0 a 5. A espessura de gordura subcutânea (EGS) foi medida através de um paquímetro, sendo tomada na face externa sobre o músculo Longissimus dorsi, entre a $12^{\mathrm{a}}$ e $13^{\mathrm{a}}$ costelas, dada em centímetros $(\mathrm{cm}), \quad$ seguindo a metodologia descrita por Cezar \& Sousa (2007).

Realizou-se a secção mediana ventral da carcaça dos animais, dividindo-a em duas hemicarcaças. A meia-carcaça esquerda foi dividida em cinco cortes comerciais: pescoço, efetuando-se um corte oblíquo entre a sétima vértebra cervical e a primeira torácica; paleta, região que tem como base anatômica a escápula, o úmero, a ulna, o rádio e o carpo; costela, $2 / 3$ da região ventral torácica sendo metade de sua base óssea correspondente ao esterno cortado sagitalmente, aproximadamente os $2 / 3$ ventrais das oito costelas e terço ventral das cinco restantes; lombo, correspondente às 6 vértebras lombares e pernil, seccionado na articulação da última vértebra lombar e a primeira sacra e na junta do tarso-metatarsiana, tendo como base óssea o ílio, o púbis, o ísquio, o fêmur, a tíbia e o tarso; que foram pesados e posteriormente avaliados.

Utilizou-se o delineamento inteiramente casualizado (DIC), com dois tratamentos (animais de pelame branco e animais de pelame preto) e quinze repetições. Os dados obtidos foram analisados através do Sistema de Análises Estatísticas e Genéticas SAEG (UFV, 1993), sendo aplicado o Teste $\mathrm{F}$ a $5 \%$ de probabilidade.

\section{RESULTADOS E DISCUSSÃO}

Os valores encontrados para o ITGU na sombra e ao sol foram 82,81 e 89,08 respectivamente; revelando $\mathrm{o}$ alto estresse térmico proporcionado pelo ambiente a esses animais, visto que valores de ITGU até 74 indicam uma situação de conforto para os animais, de 74 a 78 considera-se um estresse leve, entre 79 e 84 situação perigosa e acima de 84, indicam uma situação de emergência (BAÊTA \& SOUZA, 2010). A biometria corporal destaca-se como uma ferramenta importante na avaliação do desempenho animal. Além disso, quando analisada juntamente com outros índices zootécnicos constitui importante base de dados para a avaliação individual dos animais e para determinação de padrões morfológicos (VARGAS JÚNIOR et al., 2011). É importante ainda destacar que, segundo Santos \& Santos (2011) as características biométricas dos ovinos estão diretamente relacionadas às funções econômicas e produtivas a que se destinam e seus caracteres exteriores variam de acordo com sua função.

As medidas biométricas dos ovinos encontram-se na Tabela 1. Não houve diferença significativa para as medidas relativas à altura do dorso, altura da garupa, largura do tórax, perímetro do tórax, perímetro da coxa, perímetro da garupa e perímetro escrotal. No entanto, os ovinos brancos apresentaram maior valor $(\mathrm{P}<0,05)$ para a medida de largura da garupa quando comparados aos ovinos pretos. Isso demonstra que os ovinos brancos tiveram maior deposição de carne na carcaça, revelando que, possivelmente, os animais de pelame preto utilizaram a ativação dos meios termorregulatórios em maior escala, como o aumento da frequência respiratória por exemplo, o que requer 
Rev. Bras. Saúde Prod. Anim., Salvador, v.16, n.2, p.397-407 abr./jun.., 2015 http://www.rbspa.ufba.br ISSN 15199940

energia que poderia ter sido utilizada em outros processos produtivos $\mathrm{e}$ metabólicos,como a produção de carne. Os dados do presente estudo assemelham-se com os encontrados por Santos \& Santos (2011), ao estudarem ovinos Santa Inês no semiárido nordestino obtendo valores de largura da garupa variando entre 18,09 a $20,12 \mathrm{~cm}$. Essa medida mostra que houve um maior desenvolvimento muscular (SANTOS \& SANTOS, 2011) e indica deposição de carne de melhor qualidade (ARAÚJO FILHO et al., 2007).

Tabela 1. Médias das medidas biométricas em centímetros $(\mathrm{cm})$ dos ovinos pretos e brancos

\begin{tabular}{lcccc}
\hline Variáveis & Ovinos pretos & Ovinos brancos & CV (\%) & F \\
\hline Altura do dorso & 56,53 & 58,06 & 3,71 & 3,89 \\
Altura da garupa & 58,43 & 59,86 & 5,67 & 2,36 \\
Largura do tórax & 21,14 & 22,07 & 7,15 & 2,52 \\
Largura da garupa & 20,92 & 21,85 & 5,15 & $4,95^{*}$ \\
Perímetro do tórax & 66,53 & 68,86 & 5,35 & 3,11 \\
Perímetro da coxa & 29,26 & 30,26 & 9,45 & 0,94 \\
Perímetro da garupa & 53,96 & 56,17 & 5,80 & 3,35 \\
Perímetro escrotal & 22,00 & 23,13 & 9,89 & 1,93 \\
\hline
\end{tabular}

$\mathrm{CV}=$ coeficiente de variação; $\mathrm{F}=$ teste $\mathrm{F} ;{ }^{*}=\mathrm{P}<0,05$.

A compacidade corporal é uma medida que indica a habilidade de acúmulo de músculo na carcaça. Sua medida é importante porque permite estimar ou classificar animais quanto ao potencial de desenvolvimento corporal (ARAÚJO FILHO et al., 2007). Dessa forma, utilizar uma única medida isoladamente pode não definir as características de carcaça, mas suas combinações podem ser usadas para estabelecer índices, que permitam ajustar os dados obtidos e, assim, comparar melhor as carcaças e o desempenho animal (PAULA, 2012).

Entretanto, as informações sobre as medidas in vivo e na carcaça e suas possíveis correlações são praticamente inexistentes para ovinos adultos. Algumas medidas da carcaça podem apresentar alta correlação com seu peso e também podem ser utilizadas como indicadores de características de rendimento e qualidade e adotadas em sistemas de classificação de carcaças ovinas (PINHEIRO \& JORGE, 2010).
Na Tabela 2 são apresentados os valores referentes aos pesos, em gramas, dos não componentes da carcaça de ovinos $1 / 2$ Santa Inês $1 / 2$ Dorper. Não houve diferença significativa entre as duas pelagens no que se refere ao peso da pele, sangue, cabeça, patas, coração, pulmão, TGI cheio, TGI vazio, fígado e pênis/uretra. Houve diferença significativa com relação ao peso dos rins e testículos, sendo maior o peso dos rins nos animais de pelame escuro e maior peso de testículos atribuído aos animais com pelame claro.

A reprodução ocorre de forma apropriada apenas quando o animal está em homeostase. Em caso de estresse severo, a reprodução é normalmente o primeiro evento fisiológico a ser comprometido (KUMAR \& DE, 2013). As condições climáticas extremas impõem elevado estresse nos animais, o que afeta negativamente a sua produção e reprodução. Os processos reprodutivos no animal (macho e fềmea) são muito 
Rev. Bras. Saúde Prod. Anim., Salvador, v.16, n.2, p.397-407 abr./jun.., 2015 http://www.rbspa.ufba.br ISSN 15199940

sensíveis a interrupções por hipertermia com as consequências mais pronunciadas sendo a reduzida quantidade e qualidade da produção de esperma em machos e diminuição da fertilidade em fêmeas (SAHOO et al., 2013), devido principalmente a danos nas células reprodutivas (NEZHAD et al., 2013).

Tabela 2. Peso (em gramas) dos não componentes da carcaça de ovinos Santa Inês x Dorper de pelames preto e branco

\begin{tabular}{lcccc}
\hline Variáveis & Pelame preto & Pelame branco & CV $(\%)$ & F \\
\hline Pele & 1825,33 & 1755,06 & 13,74 & 0,61 \\
Sangue & 941,66 & 982,66 & 19,88 & 0,34 \\
Cabeça & 1256,33 & 1196,66 & 7,47 & 3,18 \\
Patas & 620,66 & 646,33 & 11,15 & 0,99 \\
Coração & 110,00 & 115,66 & 15,06 & 0,83 \\
Pulmão & 561,00 & 533,33 & 12,72 & 1,18 \\
TGI cheio & 10320,00 & 10686,00 & 11,49 & 0,68 \\
TGI vazio & 2546,33 & 2516,66 & 8,92 & 0,12 \\
Rins & 80,71 & 72,14 & 13,03 & $5,18^{*}$ \\
Fígado & 383,33 & 366,33 & 15,40 & 0,65 \\
Testículos & 172,66 & 213,33 & 27,66 & $4,35^{*}$ \\
Pênis/uretra & 60,66 & 62,66 & 14,97 & 0,35 \\
\hline
\end{tabular}

$\mathrm{TGI}=$ trato gastrointestinal; $\mathrm{CV}=$ coeficiente de variação; $\mathrm{F}=$ teste $\mathrm{F} ; *=\mathrm{P}<0,05$

A temperatura escrotal da pele dos ovinos aumenta com o aumento da temperatura ambiente. Segundo Marai et al. (2007), esta alteração afeta prejudicialmente a capacidade reprodutiva dos animais, sendo que o estresse por calor pode provocar a interrupção temporária da produção e motilidade dos espermatozóides, refletindo assim no desenvolvimento testicular, além do fato de que, de acordo com os mesmos autores, a regulação das funções biológicas, particularmente as funções reprodutivas e de comportamento em mamíferos inclui a liberação fásica e tônica de hormônios, estro e, em alguns casos, o tamanho gonadal.

De acordo com Kumar \& De (2013), a circunferência escrotal e consistência, tamanho e peso dos testículos são excelentes indicadores da capacidade de produção de esperma e funções de espermatogênese. $\mathrm{O}$ estresse térmico reduz essas medidas testiculares devido à degeneração do epitélio germinal e atrofia parcial nos túbulos seminíferos.

Uma das alterações comportamentais relativas ao estresse por conta de exposição à radiação solar intensa é a diminuição no consumo de alimentos e aumento da ingestão de água. Os rins, por sua vez, são os órgãos responsáveis pela manutenção do equilíbrio hídrico no organismo e pela filtração sanguínea, que se dá por meio de um controle hormonal bem determinado, que pode ter sido modificado devido ao estresse térmico sofrido.

Consonante a este fato, Marai et al. (2007) afirma que a exposição a temperaturas elevadas, provoca uma série de mudanças drásticas nas funções biológicas animais, que incluem distúrbios na eficiência do consumo de ração, no metabolismo de água, proteína, energia, minerais, reações enzimáticas, secreções hormonais e nos metabólitos no sangue, causando diminuição do desempenho por déficit 
Rev. Bras. Saúde Prod. Anim., Salvador, v.16, n.2, p.397-407 abr./jun.., 2015 http://www.rbspa.ufba.br ISSN 15199940

no desenvolvimento adequado do organismo animal.

$\mathrm{Na}$ Tabela 3 estão apresentados os valores referentes aos pesos e rendimentos de carcaça dos animais estudados. Não houve efeito significativo para as variáveis de peso vivo ao abate (PVA), rendimento de carcaça quente (RCQ), peso de carcaça fria (PCF), rendimento de carcaça fria (RCF) e perdas por resfriamento (PPR) em função da coloração do pelame. Os ovinos brancos apresentaram maior peso de carcaça quente (PCQ) em relação aos ovinos pretos.

Tabela 3. Peso vivo ao abate (PVA), peso de carcaça quente (PCQ), rendimento de carcaça quente (RCQ), peso de carcaça fria (PCF), rendimento de carcaça fria $(\mathrm{RCF})$ e perdas por resfriamento (PPR) de ovinos mestiços em função da coloração do pelame

\begin{tabular}{lcccc}
\hline Variáveis & Pelame preto & Pelame branco & CV $(\%)$ & F \\
\hline PVA (kg) & 30,1 & 32,5 & 11,59 & 2,85 \\
PCQ (kg) & 10,8 & 12,2 & 14,54 & $5,19^{*}$ \\
RCQ (\%) & 35,9 & 37,3 & 6,02 & 3,12 \\
PCF (kg) & 10,4 & 11,4 & 14,96 & 2,53 \\
RCF (\%) & 34,6 & 35,4 & 7,06 & 0,89 \\
PPR (\%) & 3,5 & 5 & 47,83 & 3,56 \\
\hline
\end{tabular}

$\mathrm{CV}=$ coeficiente de variação; $\mathrm{F}=$ teste $\mathrm{F} ;{ }^{*}=\mathrm{P}<0,05$.

Esse fato pode ser explicado pela característica inerente aos ovinos de pelame escuro de possuírem uma menor capacidade de reflexão dos raios solares, enfrentando estresse térmico maior e liberando energia em excesso para a manutenção da homeotermia ao invés de utilizá-la para o desenvolvimento muscular e corpóreo. Esses dados corroboram com os encontrados por McManus et al. (2011), ao encontrarem grupos fenotípicos de ovinos Santa Inês diferindo em termos de fatores físicos que afetam a tolerância ao calor, sendo que ovinos brancos mostraram os melhores parâmetros para adaptação ao calor.

Durosaro et al. (2014) relataram um menor consumo diário de ração e de água em ovelhas negras quando comparadas a ovelhas marrons e atribuíram esse fato ao impacto da radiação solar incidente, que teria provocado baixa ingestão de alimentos como forma de evitar o incremento calórico proveniente do processo digestivo. A maior ingestão de água pelas ovelhas marrons foi resultado de uma maior exigência desse nutriente para o metabolismo dos processos fisiológicos digestivos.

Os efeitos da temperatura ambiente elevada sobre o desempenho de crescimento são o produto de uma diminuição na atividade anabólica e o aumento no catabolismo do tecido. Esta diminuição no anabolismo é causada essencialmente por uma diminuição da ingestão voluntária de nutrientes essenciais, por conta da estimulação dos receptores térmicos periféricos que transmitem impulsos nervosos supressivos para o centro do apetite no hipotálamo (MARAI et al., 2007); ao mesmo tempo que ocorre o aumento do catabolismo devido à ativação e maior utilização dos mecanismos termorregulatórios para dissipar o 
Rev. Bras. Saúde Prod. Anim., Salvador, v.16, n.2, p.397-407 abr./jun.., 2015 http://www.rbspa.ufba.br ISSN 15199940

excesso de calor corpóreo, havendo grande dispêndio de energia por parte do animal.

As carcaças podem ser comercializadas inteiras ou sob a forma de cortes. Os cortes cárneos em peças individualizadas associados à apresentação do produto são importantes fatores na comercialização. $\mathrm{O}$ tipo de corte varia de região para região e principalmente entre países e a proporção desses cortes constitui um importante índice para avaliação da sua qualidade (ALVES et al., 2003).
Os pesos dos cortes comerciais dos ovinos estão apresentados na Tabela 4. Os ovinos de pelame branco apresentaram valores maiores $(\mathrm{P}<0,05)$ para o peso da perna, paleta e costelas. Isso pode ser explicado pela maior utilização de nutrientes por parte dos ovinos de pelame preto para os processos de termorregulação, desviando assim esse aporte nutricional que poderia servir para deposição de massa muscular corpórea.

Tabela 4. Peso dos cortes comerciais de ovinos de pelames preto e branco

\begin{tabular}{lcccc}
\hline Variáveis & Pelame preto & Pelame branco & CV $(\%)$ & $\mathrm{F}$ \\
\hline Lombo $(\mathrm{kg})$ & 0,656 & 0,706 & 22,5 & 0,81 \\
Pescoço $(\mathrm{kg})$ & 0,034 & 0,035 & 6,5 & 0,28 \\
Perna $(\mathrm{kg})$ & 1,668 & 1,863 & 13,9 & $4,72^{*}$ \\
Paleta $(\mathrm{kg})$ & 0,971 & 1,109 & 14,7 & $6,07^{*}$ \\
Costelas $(\mathrm{kg})$ & 1,223 & 1,479 & 19,1 & $7,37^{*}$ \\
\hline
\end{tabular}

$\mathrm{CV}=$ coeficiente de variação; $\mathrm{F}=$ teste $\mathrm{F} ; *=\mathrm{P}<0,05$.

$\mathrm{O}$ corte referente à perna foi o que apresentou o maior peso em relação aos demais, pela maior quantidade de tecido muscular que possui, corroborando os estudos de Alves et al. (2003). Com relação aos cortes lombo e pescoço, não houve diferença significativa $(\mathrm{P}>0,05)$ sobre $\mathrm{o}$ peso destes em relação à coloração do pelame dos animais, provavelmente por se tratarem de cortes menos pesados onde há menor dispêndio e requerimento de energia.

As medidas de conformação da carcaça (CONF), acabamento da carcaça (ACAB), cor (COR), marmoreio (MARM), textura (TEXT) e espessura de gordura subcutânea (EGS) encontram-se na Tabela 5. Não houve diferença significativa $(\mathrm{P}>0,05)$ para nenhuma das variáveis analisadas. Isso demonstra que o maior estresse térmico sofrido pelos ovinos de pelame preto devido à maior absorção dos raios solares não foi suficiente para provocar diferenças na qualidade da carcaça quando comparados aos ovinos brancos. Dado o exposto, percebe-se que, como afirma Marai et al. (2007), ovinos adaptados a ambientes quentes mantêm a expressão do seu potencial hereditário funcional. Em outras palavras, os animais demonstram menos variação que o normal, quando em tais condições. Consonante a isso, Costa et al. (2010) avaliando a carcaça de ovinos Dorper x Santa Inês, encontraram um conjunto de características de carcaça como melhor conformação e acabamento, cor da carne mais leve, melhor proporção de osso e maior índice de musculosidade da perna, demonstrando a adaptabilidade e o potencial de produção desses animais. 
Rev. Bras. Saúde Prod. Anim., Salvador, v.16, n.2, p.397-407 abr./jun.., 2015 http://www.rbspa.ufba.br ISSN 15199940 http://dx.doi.org/10.1590/S1519-99402015000200014

Tabela 5. Média dos valores de conformação (CONF), acabamento (ACAB), cor (COR), marmoreio (MARM), textura (TEXT) e espessura de gordura subcutânea (EGS) de ovinos Santa Inês x Dorper submetidos ao estresse calórico

\begin{tabular}{lcccc}
\hline Variáveis & Ovinos pretos & Ovinos brancos & CV $(\%)$ & $\mathrm{F}$ \\
\hline CONF (1 a 5) & 3,10 & 3,31 & 15,36 & 1,32 \\
\hline ACAB (1 a 5) & 2,70 & 2,82 & 15,13 & 0,66 \\
COR (1 a 5) & 4,31 & 4,32 & 6,42 & 0,005 \\
MARM (0 a 5) & 0,92 & 0,72 & 63,75 & 0,94 \\
TEXT (1 a 5) & 4,42 & 4,25 & 5,65 & 3,71 \\
EGS (cm) & 1,18 & 1,25 & 36,96 & 0,13 \\
\hline
\end{tabular}

$\mathrm{CV}=$ coeficiente de variação; $\mathrm{F}=$ teste $\mathrm{F}$.

Dado o exposto, pode-se concluir que houve diferenças produtivas em relação às carcaças dos ovinos Santa Inês $\mathrm{x}$ Dorper, podendo-se inferir que o estresse térmico repercutiu negativamente na condição corporal dos ovinos de pelame preto.

Contudo, mais estudos devem ser realizados relacionando a cor do pelame à carcaça de ovinos Santa Inês x Dorper.

\section{REFERÊNCIAS}

ALVES, K.S.; CARVALHO, F.F.R.; FERREIRA, M.A.; VÉRAS, A.S.C.; MEDEIROS, A.N.; NASCIMENTO, J.F.; NASCIMENTO, L.R.S.; ANJOS, A.V.A. Níveis de Energia em Dietas para Ovinos Santa Inês: Características de Carcaça e Constituintes Corporais.

Revista Brasileira de Zootecnia, v.32, n.6, p.1927-1936, 2003.

ARAÚJO FILHO, J.T.; COSTA, R.G.; FRAGA, A.B.; SOUSA, W.H.; GONZAGA NETO, S.; BATISTA, S.M.; CUNHA, M.G.G. Efeito de dieta e genótipo sobre medidas morfométricas e não constituintes da carcaça cordeiros deslanados terminados em confinamento.

Revista Brasileira de Saúde e Produção Animal [online], v.8, n.4, p.394- 404, 2007.
BAÊTA, F.C; SOUZA, C.F. Ambiência em edificações rurais: conforto animal. 2.ed. Viçosa, MG: UFV, 2010.

BERNABUCCI, U.; LACETERA, N.; BAUMGARD, L.H.; RHOADS, R.P.; RONCHI, B.; NARDONE, A. Metabolic and hormonal acclimation to heat stress in domesticated ruminants. Animal, v.4, n.7, p.1167-1183, 2010.

BRASIL. Secretaria Nacional de Irrigação. Departamento Nacional de Meteorologia. Normas climatológicas: 1961-1990. Brasília, DF: EMBRAPASPI, 1992.

BUFFINGTON, D.E.; AROCHO, A.C.; CANTON, G.H. ; PITT, D. Black globe humidity index (BGHI) as a comfort equation for dairy cows. Transactions of the ASAE, v.24, n.3, p.711-714, 1981.

CEZAR, M.F.; SOUSA, W.H.

Carcaças ovinas e caprinas: obtenção-avaliação-classificação. Uberaba: Agropecuária Tropical, 2007. $232 p$.

COSTA, R.G.; ARAÚJO FILHO, J.T.; SOUSA, W.H.; GONZAGA NETO, S.; MADRUGA, M.S.; FRAGA, A.B. Effect of diet and genotype on carcass 
Rev. Bras. Saúde Prod. Anim., Salvador, v.16, n.2, p.397-407 abr./jun.., 2015 http://www.rbspa.ufba.br ISSN 15199940

characteristics of feedlot hair sheep.

Revista Brasileira de Zootecnia, v.39, n.12, p.2763-2768, 2010.

DUROSARO, S.O.; OJO, A.; FADARE, A.O.; OLOWOFESO, O.; ILORI, B.M.; OSHO, S.O.; OGUNADE, I.M.; OZOJE, M.O. Effect of Coat Colour on Water Intake and Feed Utilization of Intensively Reared West African Dwarf Sheep in the Humid Tropics. International Journal of African and Asian Studies, v.4, p.4348, 2014.

KUMAR, D.; DE, K. Extreme climatic variables affecting male reproduction in sheep. In: SAHOO, A.; KUMAR, D.; NAQVI, S.M.K. (Eds). Climate resilient small ruminant production. Izatnagar, India: National Initiative on Climate Resilient Agriculture / Central Sheep and Wool Research Institute, 2013. p.1-106.

MAPA. Comércio exterior brasileiro. Disponível em:

$<w w w . a g r i c u l t u r a . g o v . b r>$. Acesso em: 20 jun. 2009.

MARAI, I.F.M.; EL-DARAWANY, A.A.; FADIEL, A.; ABDEL-HAFEZ, M.A.M. Physiological traits as affected by heat stress in sheep - A review. Small

Ruminant Research, v.71, p.1-12, 2007.

McMANUS, C; LOUVANDINI, H.; LANDIM, A.; MELO, C.B.; SEIXAS, L.; CARDOSO, M.; DALLAGO, B. Abate e avaliação de carcaça em ovinos. Belo Horizonte: INCT, 2010. (Série técnica: Genética).

McMANUS, C.; LOUVANDINI, H.; GUGEL, R.; SASAKI, L.C.B.; BIANCHINI, E.; BERNAL, F.E.M.; PAIVA, S.M.; PAIM, T.P. Skin and coat traits in sheep in Brazil and their relation with heat tolerance. Tropical Animal Health and Production, v.43, p.121126, 2011.
NEZHAD, F.S.; LAVVAF, A.; KARIMI, S. Influence of heat stress on DNA damage on sheep's Sertoli cells. International Research Journal of Applied and Basic Sciences, v.6, n.10, p.1396-1400, 2013.

PAULA, T.J.V.M.O. Biometria de cordeiros Dorper x Santa Inês alimentados com diferentes frações de algaroba. 2012. 88f. Dissertação (Mestrado) - Universidade Estadual do Sudoeste de Bahia, Vitória da Conquista.

PINHEIRO, R.S.B.; JORGE, A.M. Medidas biométricas obtidas in vivo e na carcaça de ovelhas de descarte em diferentes estágios fisiológicos. Revista Brasileira de Zootecnia, v.39, n.2, p.440-445, 2010.

PINHEIRO, R.S.B; SILVA SOBRINHO, A.G.; GONZAGA NETO, S; YAMAMOTO S.M.; MOURÃO, R.C.; HOMEM JÚNIOR, A.C.; SANTOS, V.C. Rendimento dos nãocomponentes da carcaça de cordeiros de diferentes genótipos. Archivos de zootecnia, v.57, n.217, p.72, 2008.

SAHOO, A.; KUMAR, D.; NAQVI, S.M.K. Strategies for sustaining small ruminant production in arid and semiarid regions. In: SAHOO, A.; KUMAR, D.; NAQVI, S.M.K. (Eds). Climate resilient small ruminant production. Izatnagar, India: National Initiative on Climate Resilient Agriculture / Central Sheep and Wool Research Institute, 2013. p.1-106.

SANTOS, F.R.; SANTOS, M.J.C. Biometria in vivo de ovinos mantidos em sistema silvipastoril no semiárido nordestino. Agropecuária Científica no Semiárido, v.7, n.3, p.21-24, 2011. 
Rev. Bras. Saúde Prod. Anim., Salvador, v.16, n.2, p.397-407 abr./jun.., 2015 http://www.rbspa.ufba.br ISSN 15199940

UNIVERSIDADE FEDERAL DE

VIÇOSA - UFV. SAEG - Sistema de

análise estatística. Viçosa, MG, 1993.

VARGAS JUNIOR, F.M.; MARTINS, C.F.; SOUZA, C.C.; PINTO, G.S.;

PEREIRA, H.F.; CAMILO, F.R;

AZEVEDO JUNIOR, N.P. Avaliação

biométrica de cordeiros pantaneiros.

Agrarian, v.4, n.11, p.60-65, 2011.

Data de recebimento: 30/04/2014

Data de aprovação: 24/04/2015 